\title{
Laboratory Investigation on Discharge Coefficient of Trapezoidal Piano Key Side Weirs
}

\author{
Minasadat Seyedjavad ${ }^{a^{*}}$, Seyed Taghi Omid Naeeni ${ }^{b}$, Mojtaba Saneie $^{\mathrm{c}}$ \\ ${ }^{a}$ PhD Student, Department of Civil Engineering, University of Tehran, Tehran, Iran. \\ ${ }^{b}$ Associate Professor, Department of Civil Engineering, University of Tehran, Tehran, Iran. \\ ${ }^{c}$ Associate Professor, Soil Conservation and Watershed Management Research Institute, Agricultural Research Education and Extension \\ Organization, P.O. Box 13445-1136, Tehran, Iran. \\ Received 02 February 2019; Accepted 23 May 2019
}

\begin{abstract}
A spillway is a hydraulic structure used to provide the controlled release of surplus waters and floods from a dam into a downstream area. A side weir is a multipurpose hydraulic structure which is constructed in water conveyance systems with a height lower than that of the canal wall. When the water surface level goes up, the side weir regulates the discharge and controls the water surface in the main canal. Besides, the side weir controls and diverts floods in dam reservoirs, diverts the flow and protects the structure against the river inundations. In this research, a laboratory investigation is performed with 16 Type-A piano key weirs and three different pier heights of 10,15 and $20 \mathrm{~cm}$. These weirs are studied for two cases of 1 and 2 . The results show that the weirs with $15 \mathrm{~cm}$ and $20 \mathrm{~cm}$ heights in both cases 1 and 2 have the highest discharge coefficient $C_{M}$ in dimensionless ratios of $0.2<\mathrm{H} / \mathrm{P}<0.4$ and $\mathrm{H} / \mathrm{P}>0.5$ respectively. Having reviewed previous studies, it could be concluded that the trapezoidal piano key side weir is capable of releasing a flow 1.2 times more than that of the linear trapezoidal labyrinth weir with 12 degrees angle and 1.87 times more than the one with 6 degrees angle, and 1.5 times more than that of the triangular labyrinth weir.
\end{abstract}

Keywords: Discharge Coefficient; Side Weir; Piano Key.

\section{Introduction}

Side weirs are multipurpose hydraulic structures which are constructed in water conveyance systems. This type of structure is used in the irrigation and drainage networks to divert the surplus water or function as the water intake. The side weir is constructed with a height lower than that of the canal wall. When the water surface increases, the side weir regulates the discharge and controls the water surface in the main canal. Besides, the side weir controls and diverts floods in dam reservoirs, diverts the flow and protects the structure against the river inundations. Figure 1 depicts a general view of the side weir in which $y_{1}$ and $y_{2}$ are the water depths upstream and downstream the weir, $\mathrm{W}$ is the weir height, B is the canal width, $\mathrm{L}$ is the weir length, $Q_{1}$ and $Q_{2}$ are the flow discharge values before and after the weir, $Q_{S}$ is the weir discharge, $V_{1}$ and $V_{2}$ are the flow velocity values before and after the weir [1].

Labyrinth weir is the basis for piano key weirs. They are often constructed with vertical walls and are much more efficient than the linear weirs. Nevertheless, the flow, especially the bottom flow, enters this type of weirs and passes

\footnotetext{
* Corresponding author: minamfsj@gmail.com 
through two vertical walls of the side crests. Then it becomes squeezed and therefore the upstream and downstream crests come up with an inappropriate hydraulic behavior.
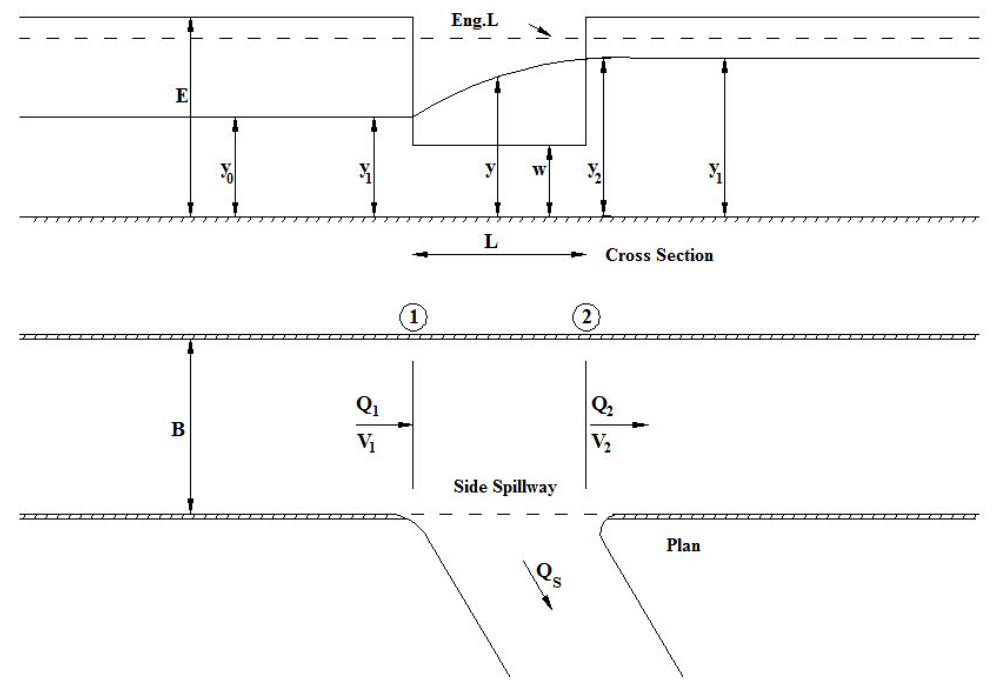

Figure 1. General View of the Side Weir [2]

In addition, the most outstanding disadvantage of this type of weirs is the large foundation area needed for constructing them on the concrete dams. The piano key weirs are a modern type of the nonlinear weirs which have been developed by Hydro coop Institute of France and the Hydraulic and Environmental laboratory of Biskara University of Algeria. In this type of weirs, as opposed to the labyrinth weirs, the bays are alternately sloped towards the reservoir and vice versa. These weirs comprise 4 different types of $\mathrm{A}, \mathrm{B}, \mathrm{C}$ and D [3] that the difference between them lies in the presence or the absence of slope in them. As seen in Figure2, Type-A is sloped both upstream and downstream, TypeB is sloped upstream, Type C is sloped downstream and Type D lacks any slope [4]. Actually, the elongation of the crest in a constant width of the weir canal and in terms of a constant water head, gives rise to the increase of the effective flow over these weirs up to 4 times more than that of the linear weirs [5].

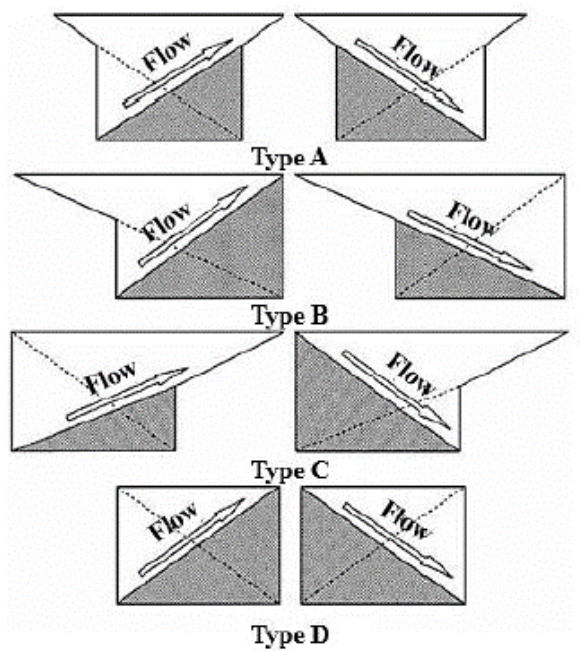

Figure 2. Different types of piano key weirs [6]

The implementation of this type of weirs needs less space comparing to that of the labyrinth weirs; thus, they could have smaller foundation area. This allows such weirs to be used in the concrete dam crests. Other advantages of the piano key weir one could refer to are: increasing the specific discharge of the weir up to $100 \mathrm{~m}^{3} / \mathrm{Sec}$, the discharge in this type of weirs is minimum 4 times more than that of the conventional weirs, increasing the reservoir capacity, being cost effective, and low maintenance cost. In 2006, the first piano key weir was constructed on Goulours Dam in France [7].The total discharge of the piano key weirs is supposed to be related to some hydraulic and geometric factors as shown in Equation 1 [8]:

$$
Q=f\left(\rho, g, \mu, H, L_{t}, P, W, W_{i}, W_{o}, B_{i}, B_{o}, L, S_{\text {in }}, S_{\text {out }}, t, R, \alpha\right)
$$

Where: $\rho$ and $\mu$ are the specific mass and viscosity of the fluid, respectively, and $\mathrm{g}$ is the acceleration of gravity. $\mathrm{H}$ is 
the total head overflowing the weir and $L_{t}$ is the total crest length. In this relation $\mathrm{P}, \mathrm{W}, W_{i}, W_{o}, B_{i}, B_{o}$ and $\mathrm{L}$ are the weir height, total width, width of the inlet key, width of the outlet key, length of the downstream apex overhang, length of upstream apex overhang and the length of the side crest, respectively. $S_{\text {in }}$ and $S_{\text {out }}$ are slopes of the inlet and outlet keys and $t$ is thickness of the weir body. Figure 3 represents a general view of a trapezoidal Type-A piano key weir.

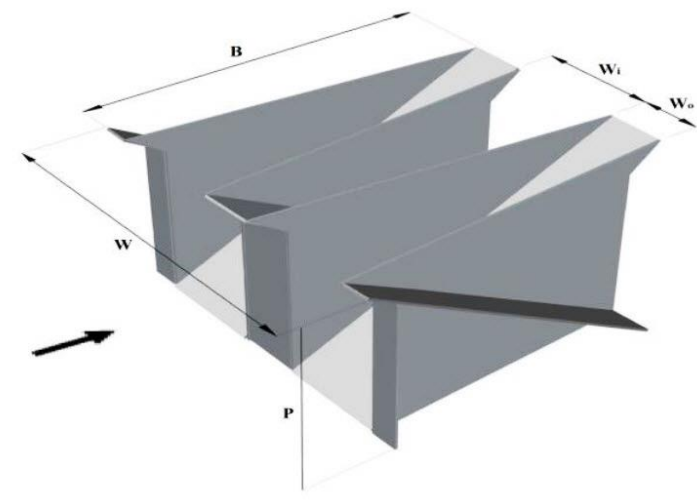

\section{Figure 3. General View of the Trapezoidal Type- A Piano Key Weir [9]}

Studies performed on these weirs correspond to the straight canals. In 2012, Javaheri and Kabiri-Samani carried out some studies to determine the discharge coefficient of the piano key weirs in the free flow state. Different tests have been conducted in this study to determine the effect of geometric and hydraulic parameters on the discharge coefficient. The aforesaid researchers proposed the following relation for $0.15<\frac{H_{0}}{P}<0.6$ as the optimal relation in determining the discharge coefficient of the Type-A piano key weirs [6].

$$
C_{d}=0.62\left(\frac{H_{0}}{P}\right)^{-0.51}\left(\frac{L}{B}\right)^{0.43}\left(\frac{a}{B}\right)^{0.18}\left(\frac{b}{B}\right)^{-0.44} \exp \left(0.87 \frac{c}{L}\right)
$$

Anderson et al. in 2012, studied the effect of different dam upstream depths and the side slopes on the discharge coefficient $C_{d}$. The results showed that the invert slope of the piano key weirs, taking into consideration the apex overhang in them, provide longer crest (L), [10]. Other researchers studied the effect of geometric parameters on the piano key weirs discharge using 3D numerical analysis. They used a piano-shaped key weir (Type-A) designed by Quamane and Lemperiere in 2003. The results showed that all these parameters could directly affect the performance of these weirs. On the other hand, the developed model could lead to good results [11]. In 2016, Mehboudi et al. conducted lab investigations on the trapezoidal piano key weirs in a straight canal. In this empirical study, the geometric parameters of TPKW models and their effects on the discharge coefficient $C_{d}$ were studied under different flow conditions. The results showed that as for the straight canal, this type of weirs can properly release a discharge amount $22 \%$ more than that of the rectangular piano key weirs [9]. In 2015, Oertel performed laboratory and numerical studies on the discharge coefficient of Type-A piano key weirs. The study results show that the dimensionless discharge coefficient could rapidly change with small changes in a small canal. Besides, in the case of increase in discharge $\left(H_{T} / P>0.15\right)$, the discharge coefficient is the same in all three types of weirs, and in case of $0.15<H_{T} / P<0.40$, the difference becomes significant [13]. To increase the discharge capacity of the linear side weirs at constant length in a canal, the application of side weir such as a side labyrinth and piano key are being studied. Karimi et al (2018) are investigating nine piano key side weirs and nine rectangular labyrinth side weirs and three linear side weirs. Free surface flow characteristics (e.g., water surface profiles, flow pattern, and deflection angles) were studied in a subcritical regime. The discharge coefficients of the side weirs were estimated using De Marchi's model. Results show significantly higher discharge coefficients for the folded shape side weirs compared to the linear side weirs. Although the results indicate no significant difference in discharge coefficients between the piano key and the rectangular labyrinth side weirs, the piano key weir is a more appropriate alternative as for the space or other construction site limitations [13].

Piano Key Weirs (PKW) are non-linear weir structures developed in the late 1990s. Thereafter, several structures studied in both laboratory and numerical models, which have been built in prototypes, especially in France. Therefore, PKWs represent an improvement and further development comparing to the Labyrinth weir, but with an additional increase of discharge capacities and a reduced footprint. Two main PKW applications can be separated in research projects: (1) on top of dams (flood release structures) and (2) in-canal applications (replacement of regular weirs). The main difference between Labyrinth and Piano Key Weirs can be found in basic geometry components. While for Labyrinth Weirs the geometry follows a kind of accordion shape with vertical weir walls (velocity distribution close to the flow surface), the PKW design is more complex and includes sloped inlet and outlet keys, placed on a small footprint area. In this context, the general flow characteristics are also modified because the inlet and outlet keys can reach flow areas close to the river bed (for in-canal application). Hence, the velocity distribution differs majorly from those found in Labyrinth weirs and with it resulting phenomena like scouring or sediment transport. The present paper summarizes 
and highlights of the current research investigations and state-of-the-art solutions for PKW designs and calculations, especially for in-canal applications. Based on this comprehensive literature review, future challenges for PKW research projects are specified. Topics like general flow characteristics, scale effects, downstream scouring, sediment transport, drift wood log jams, fish climb capability, or concrete abrasion will also be discussed in detail to identify the current and further research needs in small-scale and large-scale laboratory and numerical models [14].

Despite the widespread studies performed on the rectangular piano key weirs (RPKW) in the straight canal, studies on the trapezoidal piano key weirs as lateral weirs seem to be necessary. This paper aims to study the discharge coefficient of these weirs in the lateral form. Having had the initial depths of $y_{1}, y_{2}$ and the initial discharge values and the computational points, we could obtain the $C_{M}$ value. In this research, the trapezoidal piano key weir is used as the side weir.

\section{Materials and Methods}

\subsection{Side Weir Principles}

Flow in the side weirs is of spatially varied flow type with decreasing discharge. Many researches have been carried out on this flow type. Equation 3 represents the type of flow and its variations in a side weir, which can be considered as the $C_{M}$ of the side weir by use of the simplifications and assumptions made by De Marchi in 1934 to obtain suitable equivalents for side weirs.

$$
\frac{d y}{d s}=\frac{S_{0}-S_{f}-\left(\frac{Q}{g A^{2}}\right)\left(\frac{d Q}{d x}\right)}{1-\left(\frac{Q^{2} b}{g A^{3}}\right)}
$$

Where $s$ is the transverse axis of the side weir gap, $S o$ is the main canal gradient, $S f$ is the energy gradient, A is area of the canal $\mathrm{Q}$ is the main canal flow rate, $d Q / d \mathrm{x}=q$ is the flow rate of the width unit of the side weir, and $\mathrm{y}$ is the flow level changes. De Marchi is the assumptions considered as following:

Canal is assumed to be rectangular and prismatic, the side weirs has a short length and the specific energy between two sections 1 and 2 is constant. This is equivalent to $S_{0}-S_{f}=0$ or $S_{0}=0$ and $S_{f}=0$. The Laboratory results show that this assumption is logical as well. The side weir is equivalent to a sharp crested weir and aeration is fully performed and water exits as free flow and the energy correction factor $\alpha$, is equal to one. With regard to the above assumptions, the corresponding dynamic equation for the weirs is:

$$
x=\frac{3 B}{2 C_{M}}\left[\frac{2 E-3 W}{E-W} \sqrt{\frac{E-y}{y-W}}-3 \sin ^{-1} \sqrt{\frac{E-y}{E-W}}\right]+\text { Integral Constant }
$$

Equation 4 is known as De Marchi equation. $\mathrm{Y}$ and $\mathrm{E}$ are the depth and energy values at upstream and downstream of weir, respectively, and $\mathrm{W}$ is the pier height of the weir. As this relation is in a general form, it is used for other side weirs with different shapes [2].

\subsection{Dimensional Analysis}

The variables affecting the discharge factor of the side weir piano key weir comprise: Physical characteristics of the fluid, hydraulic characteristics of the flow, geometric characteristics of the canal and weir, and general specifications. According to the existing specifications, Equation 5 can be presented to obtain the weir discharge coefficient:

$$
\emptyset\left(S_{0}, B, B_{i}, P, L, L^{\prime}, w_{i}, w_{o}, y_{1}, y_{2}, V_{1}, g, \alpha, \delta, \mu, \rho, \sigma, C_{M}\right)=0
$$

Where: $S o$ is the main canal gradient, $B$ lateral crest length, $B i$ length of downstream overhang, $P$ weir, $L$ is total weir crest length $(L=2(2 b+2 W o)), L^{\prime}$ effective weir length, $w_{i}$ width of inlet key, $w_{o}$ width of outlet key, $y_{1}$ Depth of water upstream of the weir, $y_{2}$ Depth of water downstream of the weir, $V_{1}$ The flow velocity in the canal at the upstream of the weir, $g$ acceleration of gravity, $\alpha$ weir angle relative to the main canal, $\delta$ cone angle of weir, $\mu$ fluid viscosity, $\rho$ density of fluid, $\sigma$ surface tension and $C_{M}$ discharge coefficient. According to the theory Buckingham $\pi$, there are 16 variables and by taking $y_{1}$ (dimension $\mathrm{L}$ ), $V_{1}$ (with dimension $L T^{-1}$ ) and $\rho\left(\right.$ dimension $M L^{-3}$ ) as the three main variables (duplicate), 13 dimensionless variables are achieved. Dimensionless variables are obtained by combining any of the variables with main variables, thus:

$$
C_{M}=\emptyset_{1}\left(\frac{V_{1}^{2}}{g y_{1}}, \frac{\mu}{\rho y_{1} V_{1}}, \frac{\sigma}{\rho y_{1} V_{1}^{2}}, \frac{y_{2}}{y_{1}}, \frac{L}{y_{1}}, \frac{B}{y_{1}}, \frac{B_{i}}{y_{1}}, \frac{B}{P}, \frac{L^{\prime}}{y_{1}}, \frac{w_{i}}{w_{o}}, \alpha, \delta, S_{0}\right)
$$

In the open canal hydraulics, when the flow is turbulent, the effect of viscous forces are Insignificant compared to the inertia forces. Since the flow situation in the canals is basically turbulent, the effect of the viscous force or the 
Reynolds number $\left(\frac{\rho y_{1} V_{1}}{\mu}\right)$ is not taken into account. The effect of surface tension force, when the water depth is less than $3 \mathrm{~cm}$, will not be considered [15]. Since the tests considered the depth of water more than 3 centimetres, the effect of surface tension or the Weber number $\left(\frac{\sigma}{\rho y_{1} V_{1}^{2}}\right)$ is ignored [16]. In addition, some researchers have considered the effect of the invert slope in sub-critical flows insignificant. Consequently, the effect of $S_{0}$ is neglected [17]. Thus, by combining the dimensionless variables and considering their effect on other variables, the following relation will be obtained (Equation 7).

$$
C_{M}=\emptyset_{2}\left(F r_{1}, \frac{y_{2}}{y_{1}}, \frac{L}{B}, \frac{P}{y_{1}}, \frac{B_{i}}{L}, \frac{B}{P}, \frac{L^{\prime}}{y_{1}}, \frac{w_{i}}{w_{o}}, \delta\right)
$$

It should be noted that the Froud's number upstream of the weir in all tested models is less than one that suggests sub-critical flow condition upstream of the weir.

\subsection{Laboratory Conditions}

All tests have been conducted in a closed-loop rectangular Plexiglas flume in Soil Conservation and Watershed Management Research Institute (SCWMRI), Tehran, Iran. The study canal is $10 \mathrm{~m}$ long, $0.6 \mathrm{~m}$ wide and $0.6 \mathrm{~m}$ high. All tests have been carried out on the $0.6 \mathrm{~m}$ wide canal. To prevent flow turbulence upstream of the canal, tranquilizing racks were used at the upstream. A calibrated triangular weir was also applied to measure the flow at upstream. In addition, a calibrated rectangular sharp crested weir was used at downstream. The water surface profiles were measured at longitudinally. For this purpose, a digital depth profiler with $0.1 \mathrm{~mm}$ precision was used. The profiler accuracy is valid for a nearly stable water surface, but may decrease in highly turbulent flows. An electromagnetic velocity meter with $0.001 \mathrm{~m} / \mathrm{s}$ precision was used for velocity components to obtain parallel $\left(V_{x}\right)$ and perpendicular $\left(V_{Y}\right)$ to the side weir. The profiler and the velocity meter could move on a rail in both $\mathrm{X}$ and $\mathrm{Y}$ directions. Flow rates at the main and the collection canal were measured by a calibrated $90^{\circ} \mathrm{V}$-notched and a rectangular weir, respectively. Figure 6 shows a general view of the laboratory. In this research, 16 models of Type-A trapezoidal weirs have been studied in two cases of 1 and 2. The weirs had $3 \mathrm{~mm}$ thickness made of Plexiglas. The tests were carried out preventing the effects of viscosity and surface tension over the weir and considering a height of more than $3 \mathrm{~cm}$ [17]. Table 1 represents the specifications of the performed tests. In this research, for investigating the effect of number of inlet cycles, the weirs were tested at two different directions of the side weirs located in the main canal. Figures 4 and 5 show the weir locations for the two mentioned cases.

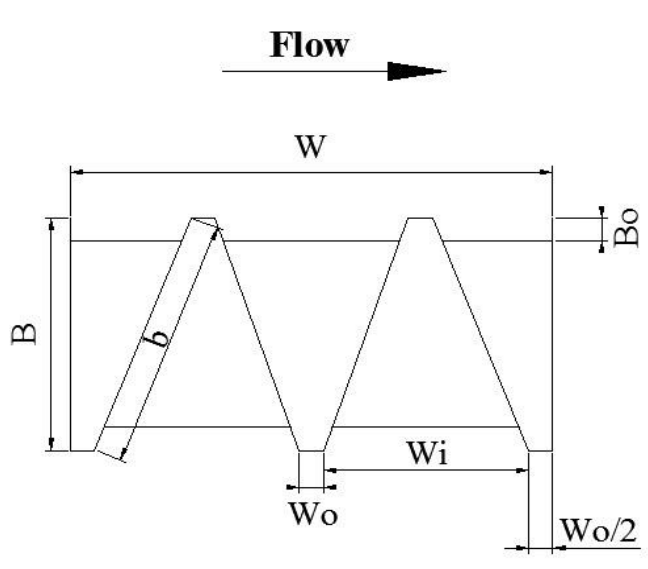

Figure 4. Location of Weir in Case 1

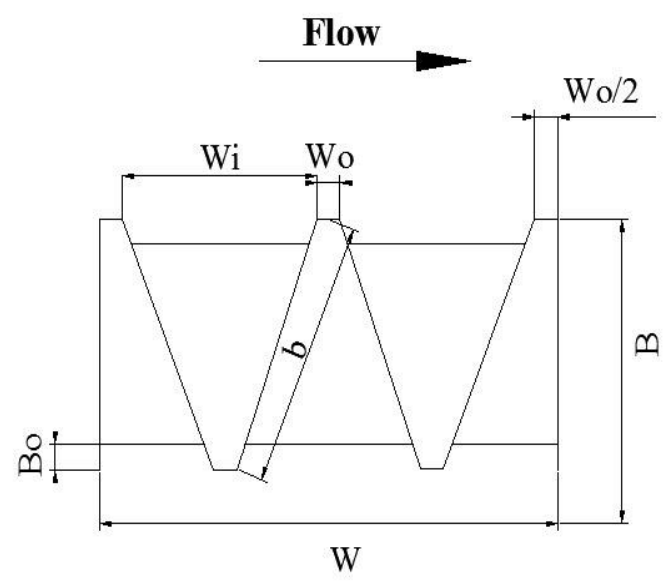

Figure 5. Location of Weir in Case 2

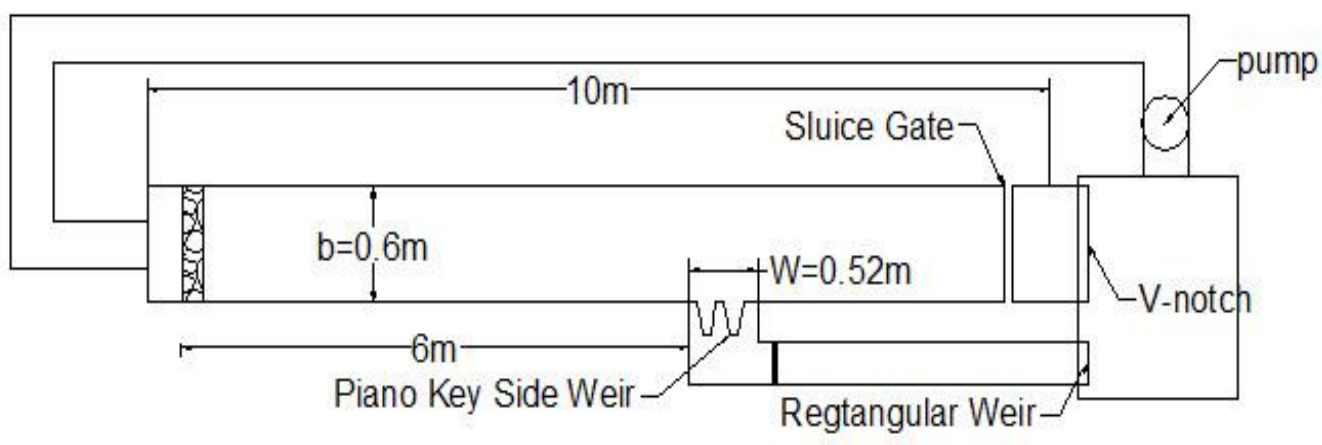

Figure 6. Plan of the Laboratory 
Table 1. Structures Specifications and Performed Tests

\begin{tabular}{ccccccccc}
\hline Weir Type & $\mathbf{B}(\mathbf{c m})$ & $\mathbf{P}(\mathbf{c m})$ & $\mathbf{b}(\mathbf{m})$ & $\mathbf{W}(\mathbf{m})$ & $\mathbf{W}_{\mathbf{i}} / \mathbf{W}_{\mathbf{o}}$ & $\mathbf{L} / \mathbf{W}$ & $\mathbf{Q}_{\mathbf{1}}(\mathbf{L} / \mathbf{s})$ & $\mathbf{F r}$ \\
\hline PKSW & 30 & $10,15,20$ & 0.6 & 0.52 & $1.33-4$ & $2.6-5.9$ & $30-60$ & $0.15-0.60$ \\
PKSW & 50 & $10,15,20$ & 0.6 & 0.52 & $1.33-4$ & $2.6-5.9$ & $30-60$ & $0.15-0.60$ \\
PKSW & 70 & $10,15,20$ & 0.6 & 0.52 & $1.33-4$ & $2.6-5.9$ & $30-60$ & $0.15-0.60$ \\
CSW & - & $10,15,20$ & 0.6 & 0.52 & - & - & $30-60$ & $0.15-0.60$ \\
\hline
\end{tabular}

\section{Discussion and Results}

\subsection{Comparison between Location 1 and 2 for Present Study}

As seen in Table 1, three different piers $(\mathrm{P}=10,15$ and $20 \mathrm{~cm})$ and three different widths $(\mathrm{B}=30,50$ and $70 \mathrm{~cm})$ in Type-A of the trapezoidal piano key weir have been studied in this research. Three weirs with different side wall lengths and $10 \mathrm{~cm}$ pier are shown in Figures 7 to 9.

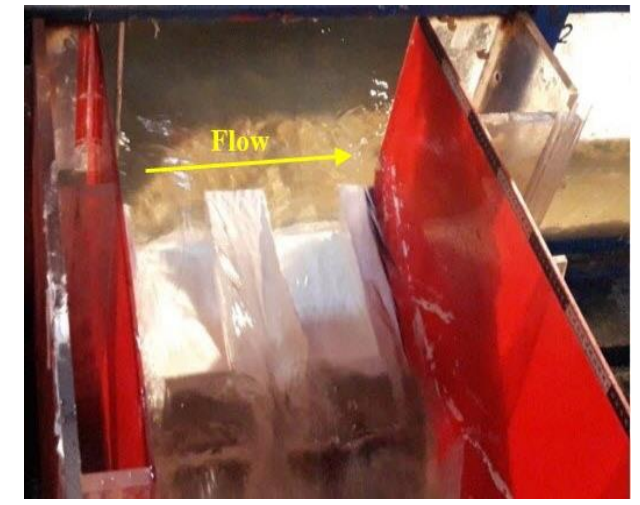

Figure 7. Weir with $30 \mathrm{~cm}$ side wall length and $10 \mathrm{~cm}$ pier

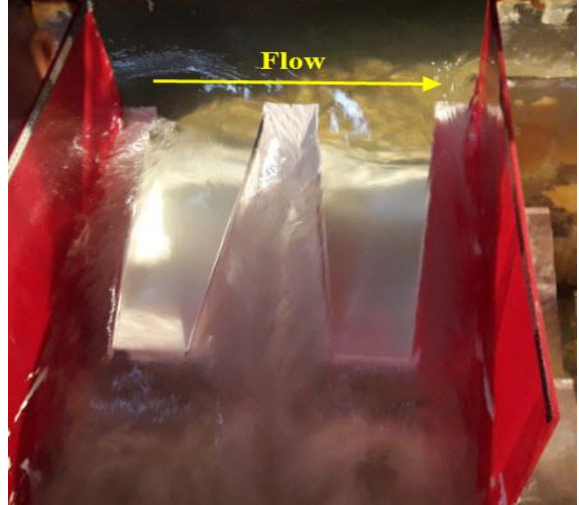

Figure 8. Weir with $50 \mathrm{~cm}$ side wall length and $10 \mathrm{~cm}$ pier

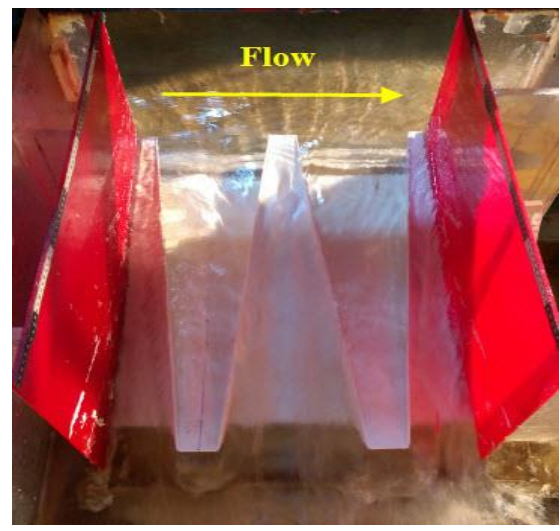

Figure 9. Weir with $70 \mathrm{~cm}$ side wall length and $10 \mathrm{~cm}$ pier

In order to study the accuracy of the performance of these weirs, comparison was made between various dimensionless parameters applied in the measurements using the data of other tests results provided by other researchers. Thereafter, the results obtained in fully similar laboratory conditions are first reviewed using a kind of piano key weirs, and parameters such as pier $(\mathrm{P})$ and the angle of side walls $(\alpha)$ are studied, and then other dimensionless parameters including $\mathrm{L} / \mathrm{W}, \mathrm{L} / \mathrm{B}$ and $\mathrm{B} / \mathrm{P}$ ratios are assessed. With regard to the results given in Figure 10 , the weir with $\mathrm{P}=10 \mathrm{~cm}$, and widths $B=50 \mathrm{~cm}$ and $B=70 \mathrm{~cm}$ exhibits a higher $C_{M}$ coefficient (obtained by De Marchi Relation) in comparison with the weir with $B=30 \mathrm{~cm}$. The $C_{M}$ value, where $0.2<H / P<0.4$, and the weir is in Case 1 , is in the range $1.3<C_{M}<1.9$, and where $0.5<\mathrm{H} / \mathrm{P}<1.0$, the $\mathrm{C}_{\mathrm{M}}$ value is in the range $0.7<\mathrm{C}_{\mathrm{M}}<1.7$. When studying the weir in Case 2 shown in Figure 11, with $\mathrm{P}=10 \mathrm{~cm}$, where $0.2<\mathrm{H} / \mathrm{P}<0.4$, the $\mathrm{C}_{\mathrm{M}}$ value is in the range $1.3<\mathrm{C}_{\mathrm{M}}<1.9$ and where $0.5<\mathrm{H} / \mathrm{P}<1.0$ the $\mathrm{C}_{\mathrm{M}}$ value is in the range $0.7<C_{M}<1.7$. For $P=15 \mathrm{~cm}$, considering the obtained data from the weir tests in Case 1 and regarding Figure 10 , one could presume that with a greater side wall length $(\mathrm{B})$, we would have a higher discharge coefficient value. In these conditions, where $0.2<\mathrm{H} / \mathrm{P}<0.4$, the discharge coefficient value would be higher, and for $\mathrm{H} / \mathrm{P}>0.5$, the weir efficiency is practically reduced. With $\mathrm{B}=50 \mathrm{~cm}$, where $0.2<\mathrm{H} / \mathrm{P}<0.4$, the discharge coefficient value varies from 2.1 to 1.36 , and where $\mathrm{H} / \mathrm{P}>0.5$, the $\mathrm{C}_{\mathrm{M}}$ value varies from 1.02 to 0.82 . As seen, with $\mathrm{P}=15 \mathrm{~cm}$, where $\mathrm{B}$ decreases, $\mathrm{L}$ is also decreased and as a result the discharge coefficient value is also decreased. 


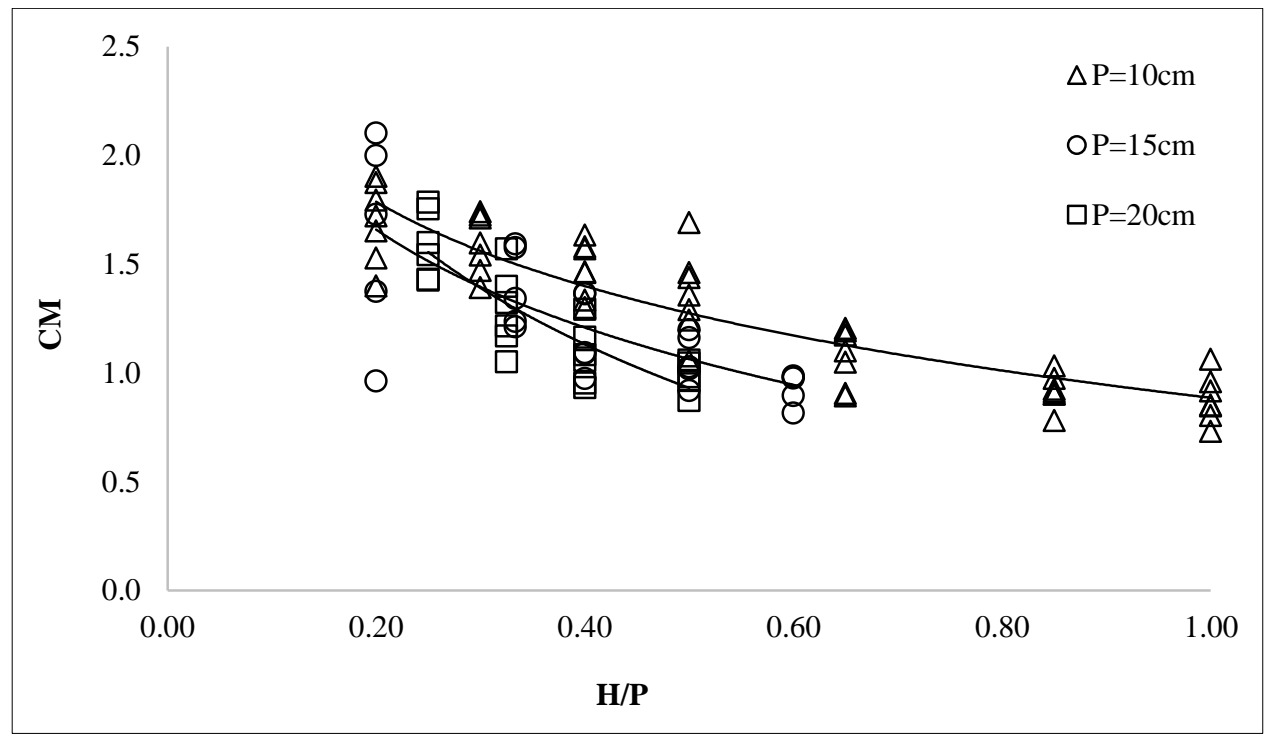

Figure 10. Discharge Coefficient Value for the Weir in Case 1

With $\mathrm{P}=20 \mathrm{~cm}$ in all the obtained data, it can be concluded that the longer the weir wing width is (B), the higher the discharge coefficient value would be. With $B=70 \mathrm{~cm}$, where $0.2<H / P<0.4$, the $C_{M}$ value varies from 1.78 to 1.29 , and it is notable that in this type of the weirs, the $\mathrm{H} / \mathrm{P}$ ratio higher than 0.4 is incomputable. It should be mentioned that the $C_{M}$ value for the weir Case 2 would be lower. While investigating the $C_{M}$ value for $B=50 \mathrm{~cm}$, it is seen that it varies from 1.76 to 1.06 , and a relatively higher head loss occurs with respect to the $\mathrm{B}=70 \mathrm{~cm}$ case at $\mathrm{H} / \mathrm{P}=0.2$, and this value decreases by about 0.2 units. It should be noted that in this case, the $C_{M}$ value in Case 2 is also lower than Case 1 . With $\mathrm{P}=20 \mathrm{~cm}$, where $\mathrm{B}=30 \mathrm{~cm}$, the $\mathrm{C}_{M}$ value varies from 1.6 to 0.93 and a considerable difference is seen between $\mathrm{B}=50 \mathrm{~cm}$ and $B=30 \mathrm{~cm}$ cases. Therefore, it could be concluded that there is difference between $C_{M}$ values for two cases of $B=30 \mathrm{~cm}$ and $\mathrm{B}=50 \mathrm{~cm}$ and the $\mathrm{C}_{\mathrm{M}}$ value for case $\mathrm{B}=50 \mathrm{~cm}$ is 0.13 higher than the other two cases.

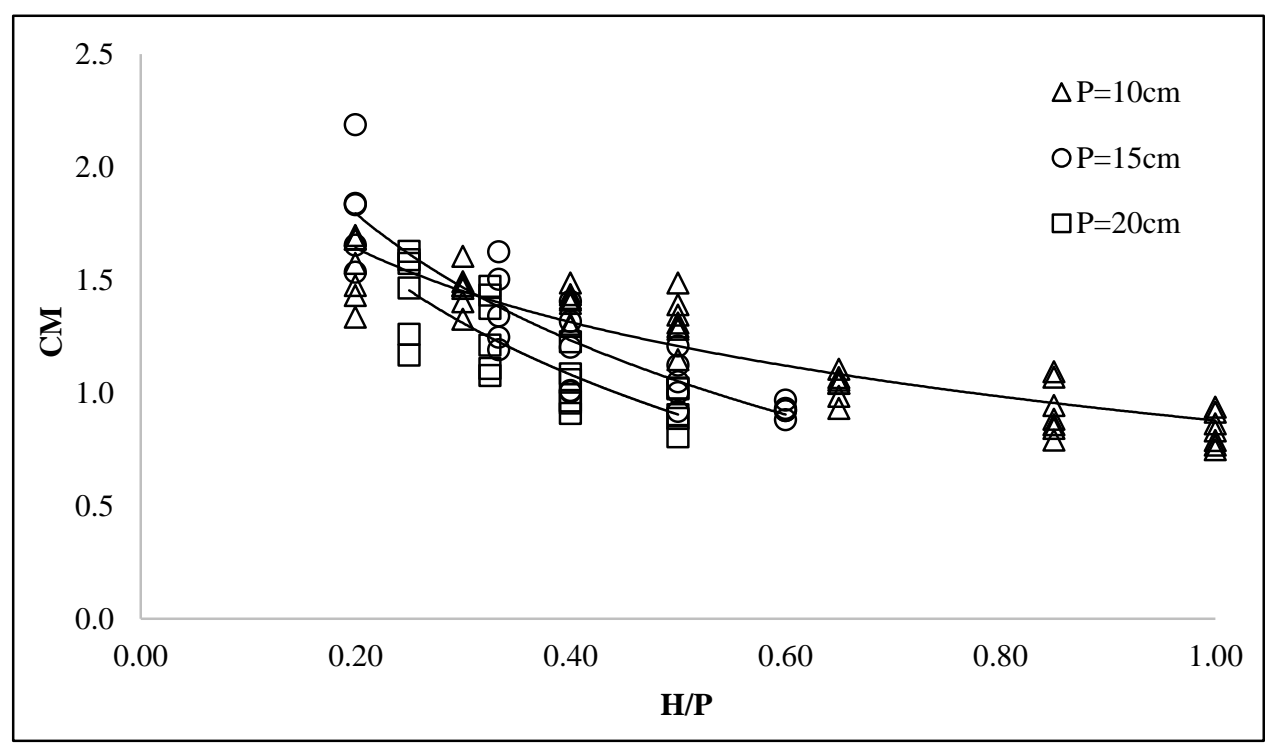

Figure 11. Discharge Coefficient Value for the Weir Case 2

\subsection{Comparison to Similar Conditions}

To study the validity of this research and verifying that the discharge coefficient value $C_{M}$ has been optimized in the present study, the results of this research were compared to similar conditions. In the comparison made among the weirs results, the rectangular piano key weir and the trapezoidal piano key weir were compared with two equal lengths of $2 \mathrm{~m}$ and $3.4 \mathrm{~m}$. Figure 12 shows the test results for weirs in Case 1 . In case of $0.2<\mathrm{H} / \mathrm{P}<0.4$, when the weir is $2 \mathrm{~m}$ long, the discharge coefficient of $C_{M}$ in the side trapezoidal piano key weir would be between 1.73 and 0.93 that this coefficient in similar ratio in a rectangular piano key side weir would be between 1.15 and 0.85 . In case of $\mathrm{H} / \mathrm{P}>0.5$, the discharge coefficient of $C_{M}$ in the side trapezoidal piano key weir would be between 1.36 and 0.82 that this coefficient in similar ratio in a rectangular piano key side weir would be between 1.07 and 0.71 . The next comparison is for the case in which weirs are $3.4 \mathrm{~m}$ long. In this case, the discharge coefficient of $C_{M}$ in the side trapezoidal piano key weir would be between 
1.72 and 0.95 that this coefficient in similar ratio in a rectangular piano key side weir would be between 1.72 and 1.18 . In case of $\mathrm{H} / \mathrm{P}>0.5$, the discharge coefficient of $C_{M}$ in the side trapezoidal piano key weir would be between 1.47 and 0.87 that this coefficient in similar ratio in a rectangular piano key side weir would be between 1.21 and 0.81 .

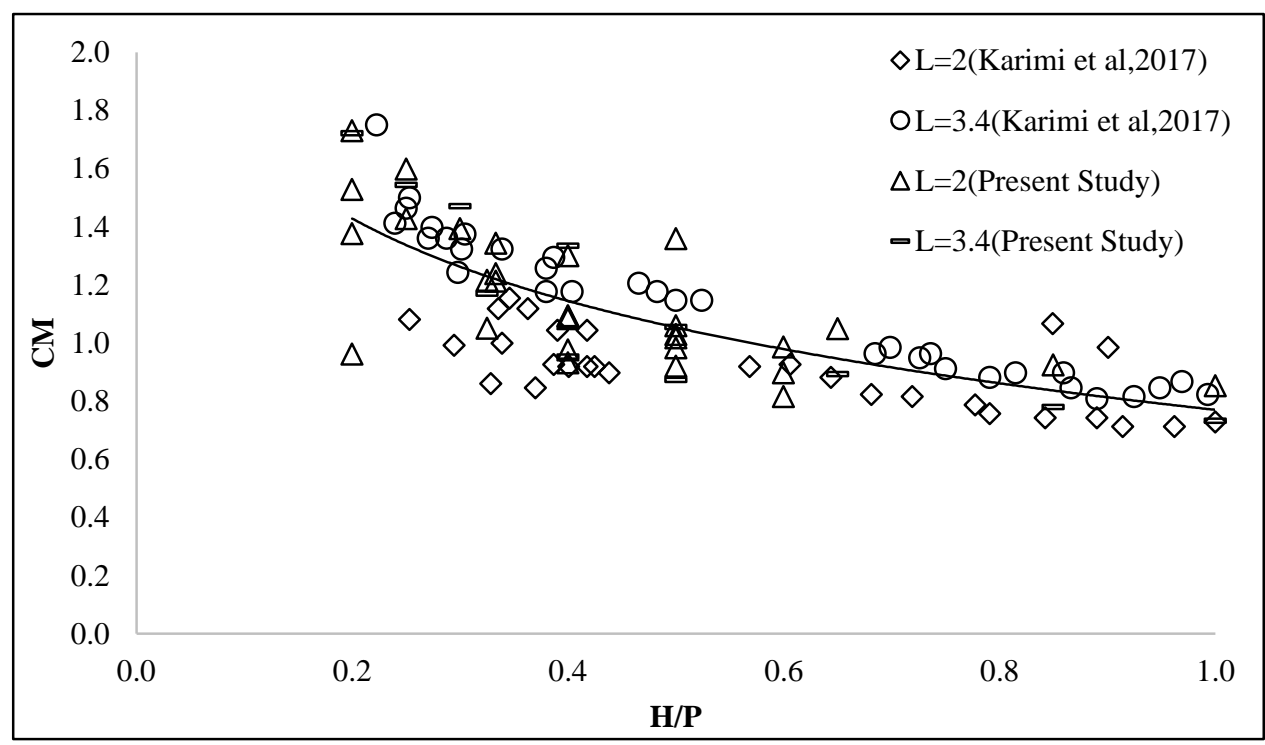

Figure 12. Comparison between the Coefficients Values for Case 1 of Trapezoidal and Rectangular Weirs

Figure 13 represents the test results for weirs in Case 2. In case of $0.2<\mathrm{H} / \mathrm{P}<0.4$, when the weir is $2 \mathrm{~m}$ long, the discharge coefficient of $\mathrm{C}_{\mathrm{M}}$ in the side trapezoidal piano key weir would be between 1.83 and 0.9 that this coefficient in similar ratio in a rectangular piano key side weir would be between 1.15 and 0.85 . In case of $\mathrm{H} / \mathrm{P}>0.5$, the discharge coefficient of $\mathrm{C}_{\mathrm{M}}$ in the side trapezoidal piano key weir would be between 1.28 and 0.8 that this coefficient in similar ratio in a rectangular piano key side weir would be between 1.07 and 0.71 . The next comparison is for the case in which weirs are $3.4 \mathrm{~m}$ long. In this case, the discharge coefficient of $\mathrm{C}_{\mathrm{M}}$ in the side trapezoidal piano key weir would be between 1.70 and 0.96 that this coefficient in similar ratio in a rectangular piano key side weir would be between 1.72 and 1.18. In case of $H / P>0.5$, the discharge coefficient of $C_{M}$ in the side trapezoidal piano key weir would be between 1.15 and 0.77 that this coefficient in similar ratio in a rectangular piano key side weir would be between 1.21 and 0.81 . As seen in graphs 3 and 4, the trapezoidal piano key weir releases the discharge more appropriate than the rectangular piano key side weir.

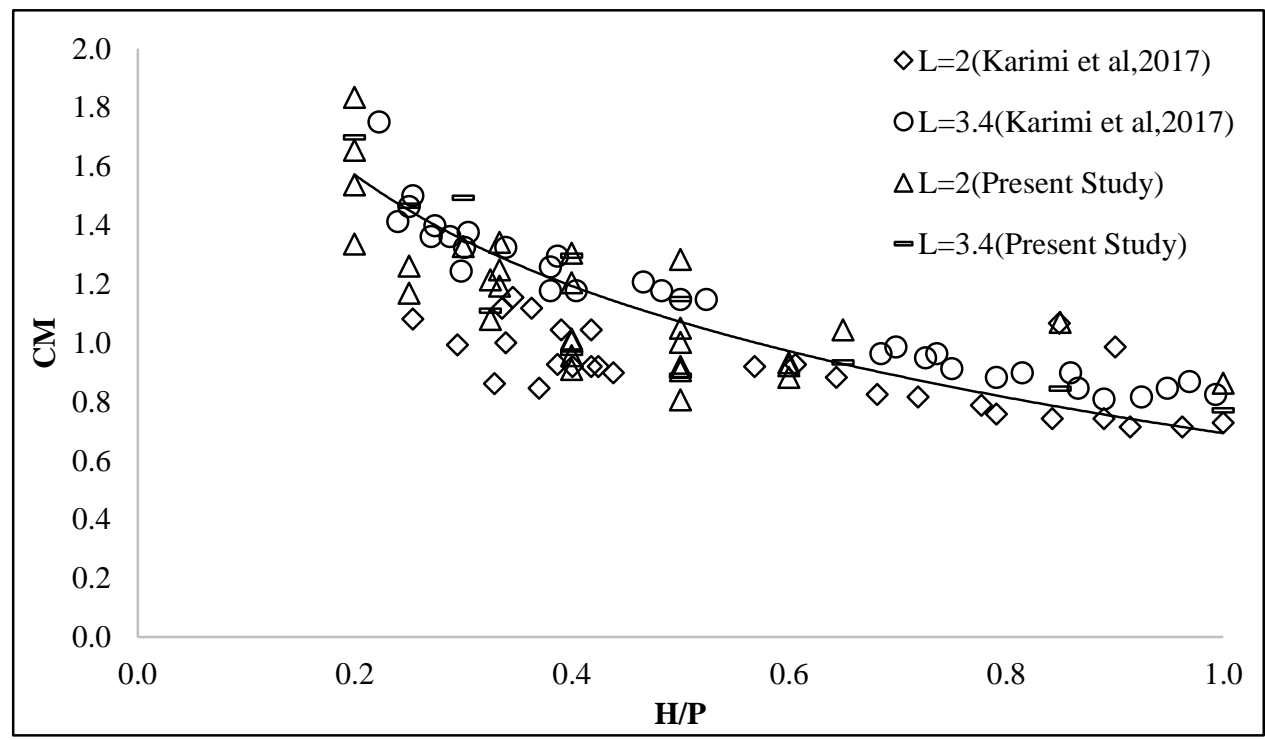

Figure 13. Comparison between the Coefficients Values for Case 2 of Trapezoidal and Rectangular Weirs

\subsection{Comparison between Present Study and Other Piano Key Weir Researches}

Another comparison made in this study was in accordance with the results of the piers constant parameter of weirs (P). This comparison was made among the values obtained from the linear rectangular piano key weirs and linear circular labyrinth weirs with uniform piers of 10 and $20 \mathrm{~cm}$. With regard to the former studies and the results obtained, it is 
expected that the side weir values be less than the linear weir. As shown in Figure 14, with regard to the dimensionless ratio $\mathrm{H} / \mathrm{P}$ in weirs, the maximum and minimum $\mathrm{C}_{\mathrm{d}}$ values in the trapezoidal piano key weirs are 0.92 and 0.15 respectively. As seen in Figure 14, in the linear rectangular piano key weirs and with similar conditions, the maximum and minimum obtained $C_{d}$ values are 0.75 and 0.38 respectively for $\mathrm{P}=10 \mathrm{~cm}$ which exhibits a discharge coefficient value equal to 1.2 times more than that of the weirs for the trapezoidal piano key weirs. But in the case of $\mathrm{H} / \mathrm{P}<0.2$, linear weir has more appropriate function.

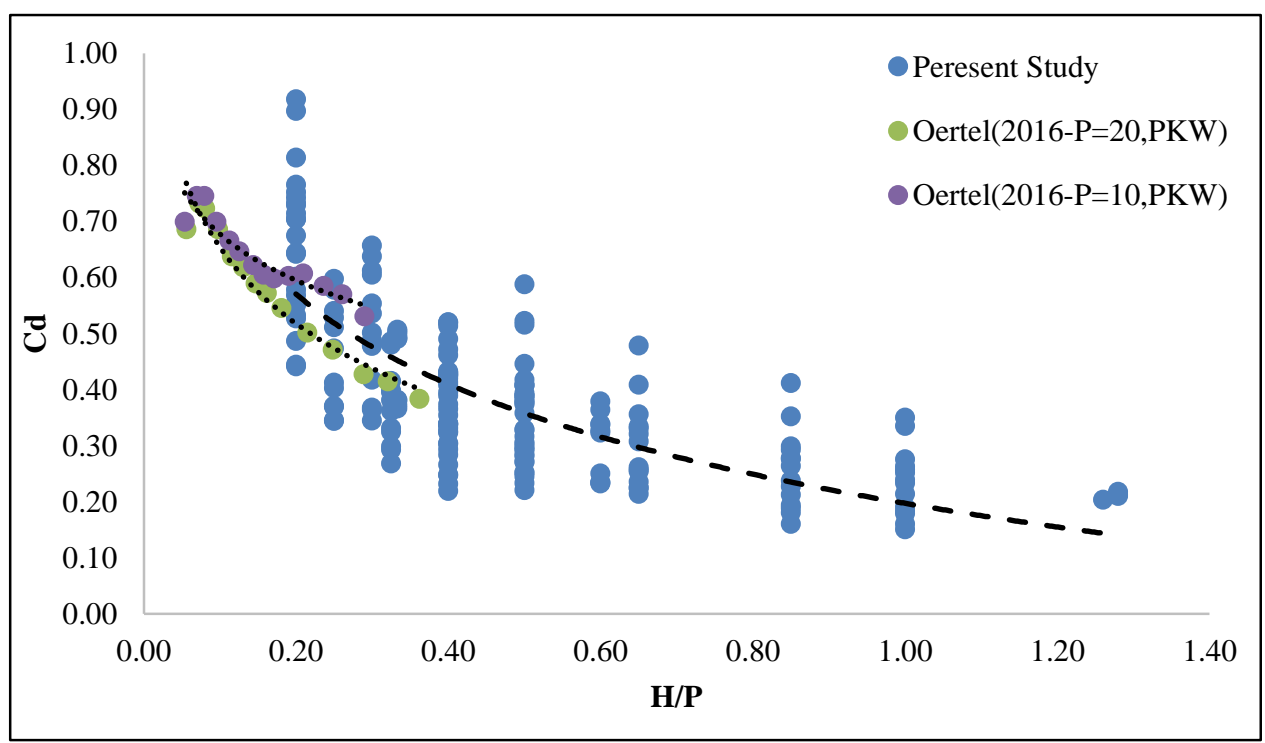

Figure 14. Comparison between the Flow Discharges based on the Pier Height

Another comparison made between the results of this research is based on the constant parameter of angle between weirs $(\alpha)$. The results corresponds to the comparison between the side labyrinth weir and trapezoidal side piano key weir. As seen in Figure 15, with regard to the dimensionless ratio $\mathrm{H} / \mathrm{P}$ of the weirs, the maximum and minimum $C_{d}$ value obtained in the trapezoidal piano key weirs for 12 degrees are 0.71 and 0.35 respectively. Whereas, these values in the trapezoidal labyrinth weirs are 0.58 and 0.47 respectively. This shows that its discharge is 1.2 times more that of the trapezoidal piano key weirs in case of $\mathrm{H} / \mathrm{P}<0.2$. For 6 degrees angle, the maximum and minimum $C_{d}$ values obtained are 0.92 and 0.15 for the trapezoidal piano key weirs respectively. Whereas these values in the trapezoidal labyrinth weirs are 0.49 and 0.20 respectively. Therefore, the trapezoidal piano key weirs have a discharge coefficient value of 1.87 times greater for this angle with similar flow conditions. Figure 16 shows the discharge coefficient value for the 6 degrees angle.

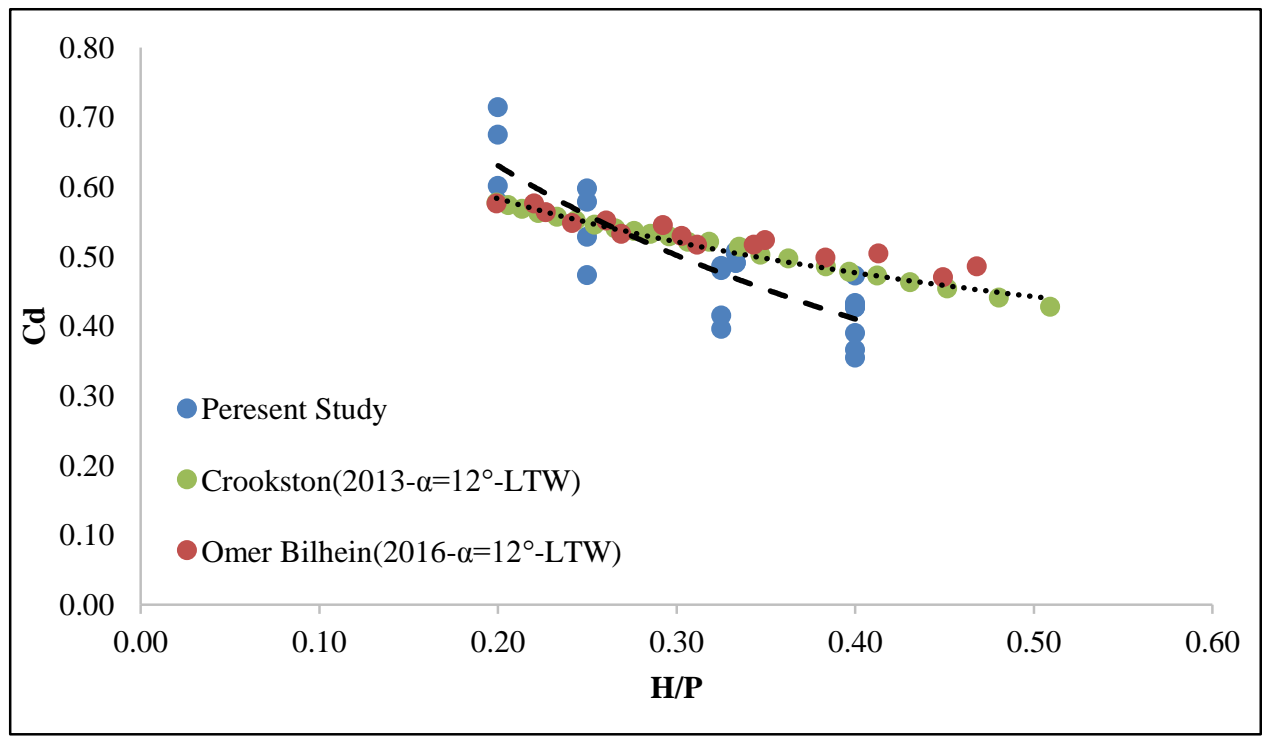

Figure 15. Comparison between the Discharge Coefficients Based on 12 Degrees Angle 


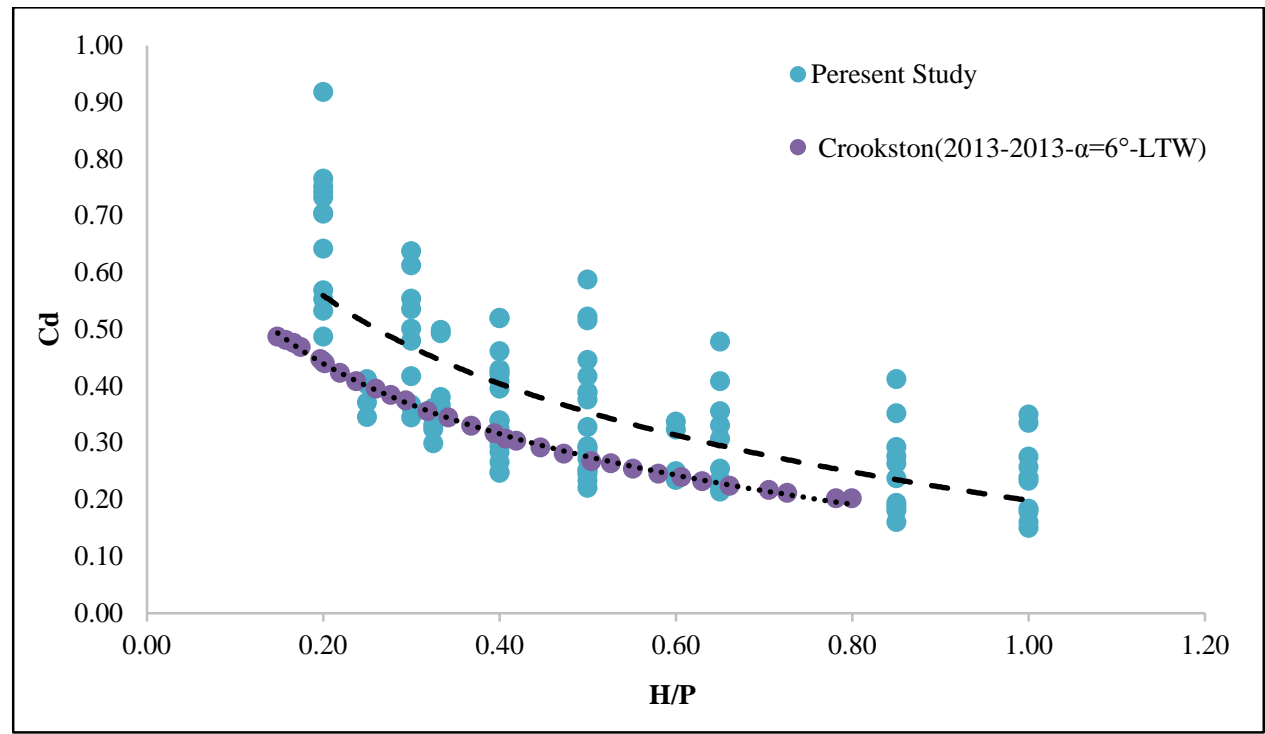

Figure 16. Comparison between the Discharge Coefficients Based on 6 Degrees Angle

In accordance with the results obtained based on the dimensionless parameter of $\mathrm{L} / \mathrm{W}$, and with respect to the previous articles, and as shown in Figure 17, the maximum $C_{d}$ values obtained for the trapezoidal piano key weirs for different $\mathrm{L}$ values of 1.6, 2.4 and $3 \mathrm{~m}$ are $0.92,0.73$ and 0.55 , respectively. Besides, the corresponding minimum $C_{d}$ values are $0.30,0.22$ and 0.22 respectively. This comparison is actually made based on the dimensionless parameter $\mathrm{L} / \mathrm{W}$, where $\mathrm{W}$ is $0.52 \mathrm{~m}$ in this research and in Kabiri-Samani's study this value is $0.4 \mathrm{~m}$; but, the $\mathrm{L} / \mathrm{W}$ ratio had similar values and were comparable. The maximum $C_{d}$ values obtained from Kabiri-Samani's study were related to the rectangular linear piano weirs and for the foregoing $\mathrm{L}$ values were $0.73,0.92$ and 1.46 , respectively. In addition, the corresponding minimum values were $0.44,0.53$ and 0.58 , respectively. In this dimensionless parameter, the trapezoidal piano key weir in the side position could have more discharge than the rectangular linear piano key weir in the case of $\mathrm{L}=1.6 \mathrm{~m}$. According to other comparisons made in this regard, and as expected, the discharge factor value in the linear weir is more than the side weir.

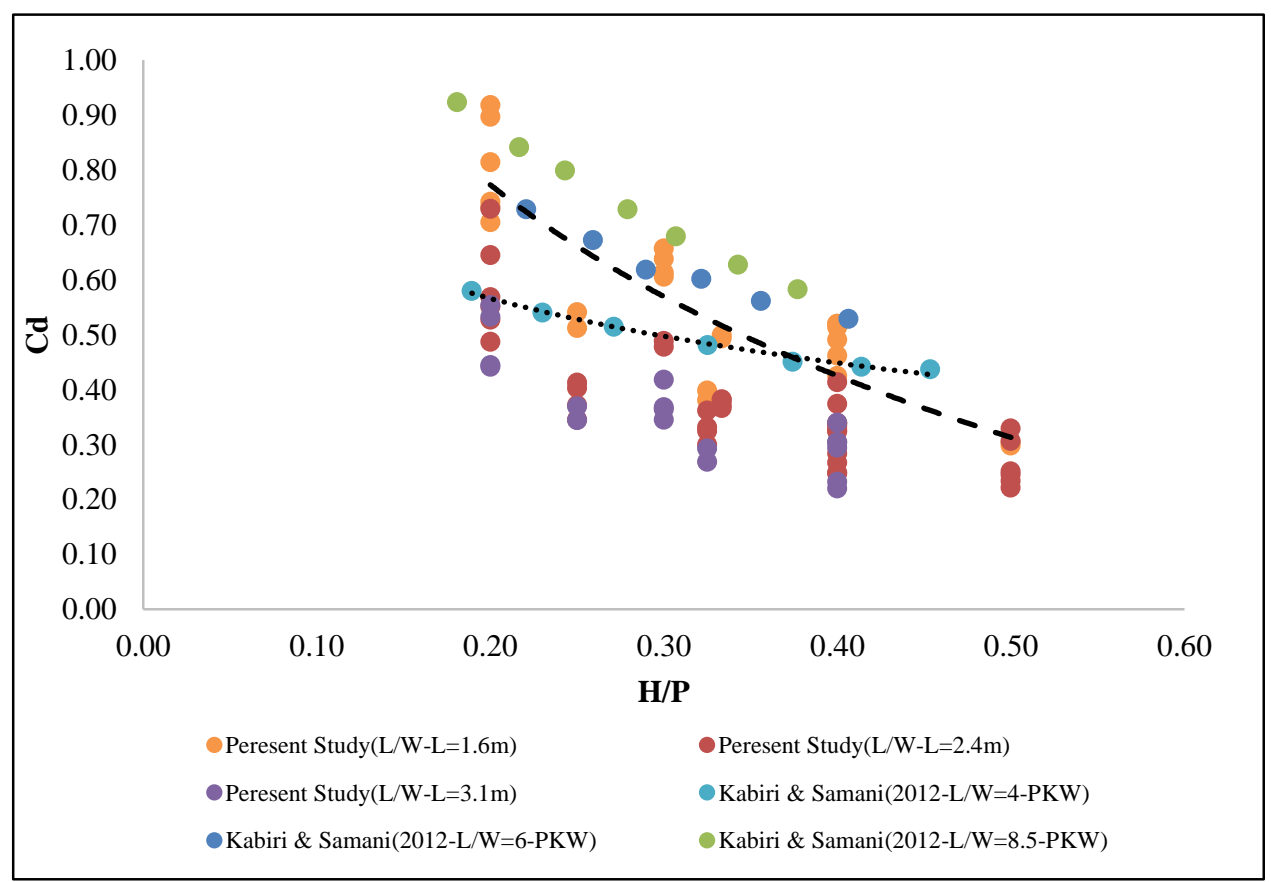

Figure 17. Comparison between the Discharge Coefficients based on L/W Ratio

Figure 18 represents the comparison made among the discharge coefficient of the trapezoidal piano key weir and linear rectangular and side trapezoidal piano key weir. As seen, up to the ratio of $0.2<\mathrm{H} / \mathrm{P}<0.4$, the $C_{d}$ coefficient in the side weir is 1.1 more than that of the linear weir, but the efficiency of the side weir decreases in case of $H / P>0.5$. As shown, the discharge coefficient in the trapezoidal piano key weir in both side and linear cases is 1.55 times more than that of the rectangular linear piano key weir. 


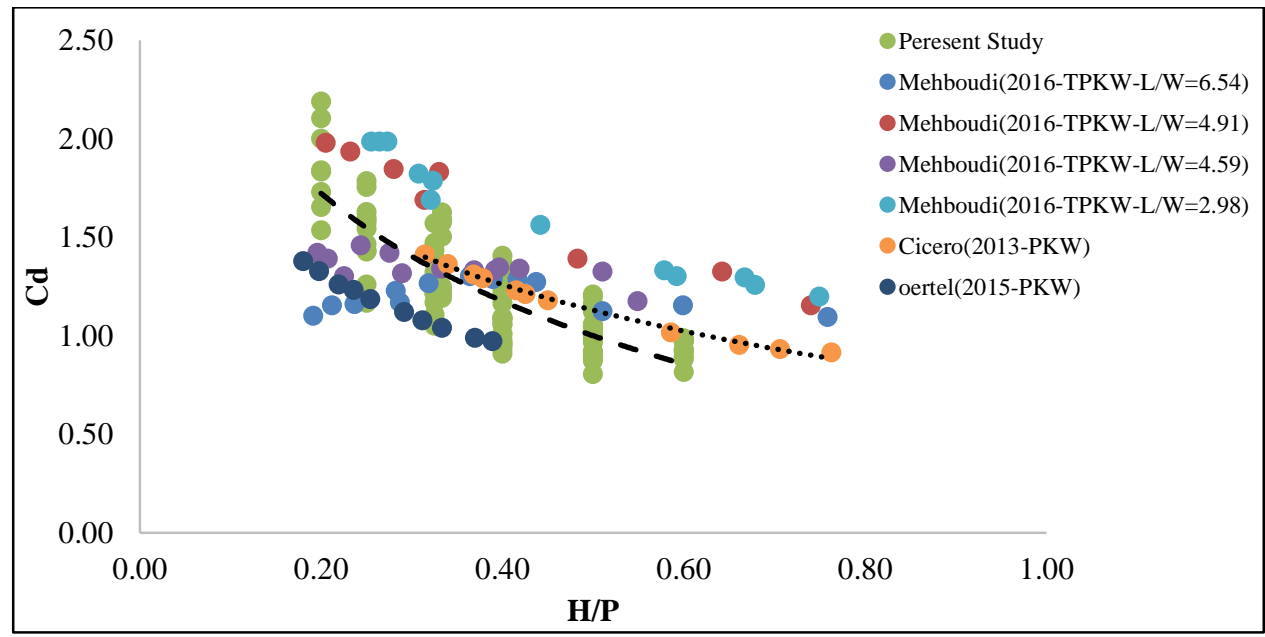

Figure 18. Comparison between the Discharge Coefficients Based on Different $\mathrm{L} / \mathrm{W}$

Figure 19 depicts the comparison between the $C_{d}$ coefficients of the linear rectangular piano key weir and side trapezoidal piano key weir based on the dimensionless parameter of $\mathrm{B} / \mathrm{P}$. As seen in this figure, the $C_{d}$ coefficient in all $\mathrm{H} / \mathrm{P}$ ratios in the linear rectangular piano key weir is 1.5 times more than that of the side trapezoidal piano key weir.

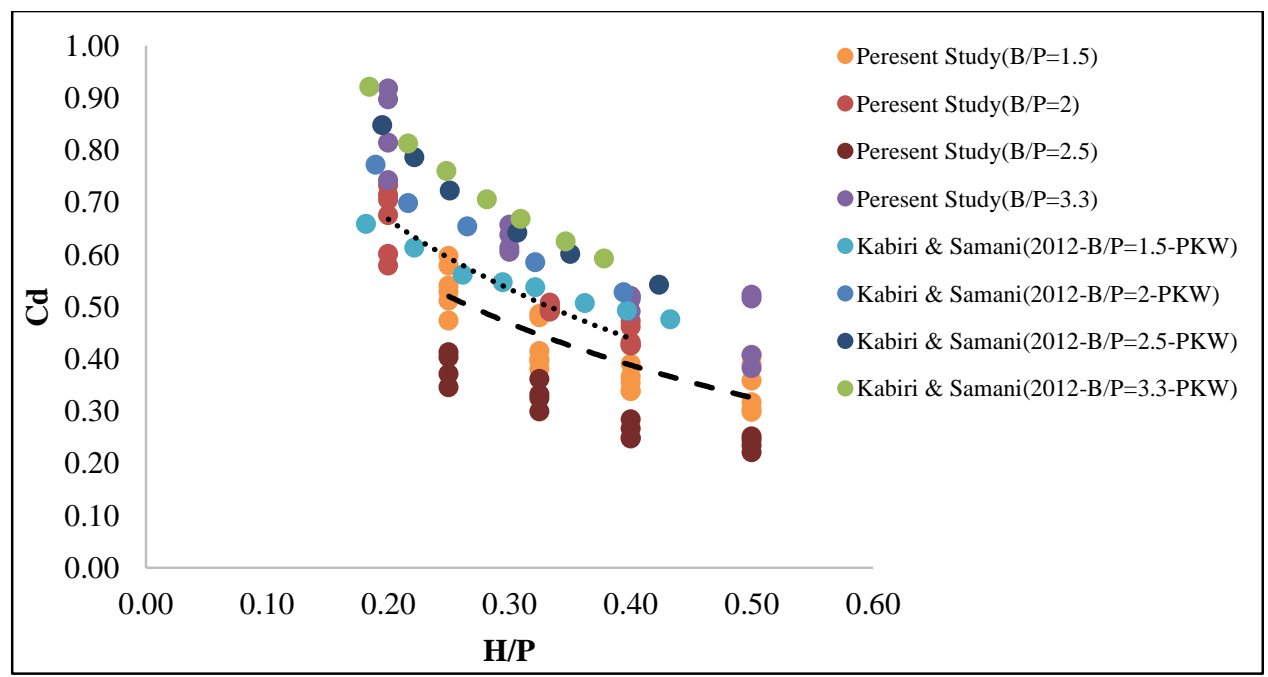

Figure 19. Comparison Made among the Discharge Coefficients Based on Various B/P Ratios

Figure 20 shows the comparison made between the $C_{d}$ values of the labyrinth triangular side weir and side trapezoidal piano key weir. As seen in this figure, in all $\mathrm{H} / \mathrm{P}$ ratios, the $C_{d}$ value of the side trapezoidal piano key weir is 1.5 times more than that of the labyrinth triangular side weir.

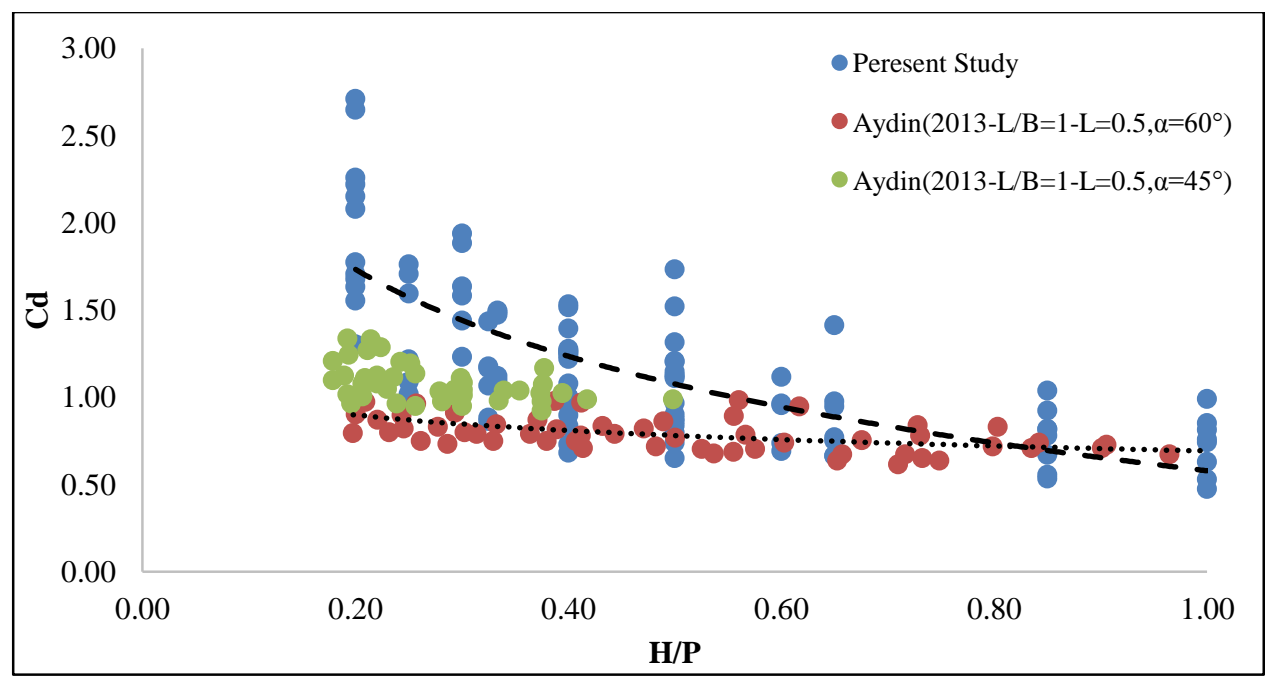

Figure 20. Comparison between the discharge coefficients of the labyrinth triangular side weir and side trapezoidal piano key weir 
Figure 21 represents the amounts of primary and secondary energies in this research concerning the side trapezoidal piano key weirs. These values are appropriately close to each other. This indicates the good precision of this research and the reliability of obtained discharge coefficients. Figure 22 shows the comparison between the discharge coefficient of $C_{d}$ computed using $Q=\frac{2}{3} \sqrt{2 g} C_{d} L H^{1.5}$, where $\mathrm{L}$ is the effective length of the weir and $\mathrm{H}$ is the height of water upstream of the weir, and the De $C_{M}$ of Equation 1 shows the Marchi coefficient equation in this research. According to this figure, and in terms of the dimensionless parameter $\mathrm{H} / \mathrm{P}$, in case of $0.2<\mathrm{H} / \mathrm{P}<0.4$, the computed and observed discharge coefficients are nearly close to each other and the resulted difference is very little. But, in the case of $\mathrm{H} / \mathrm{P}>0.5$, the difference between the computed and observed discharge coefficients is too much.

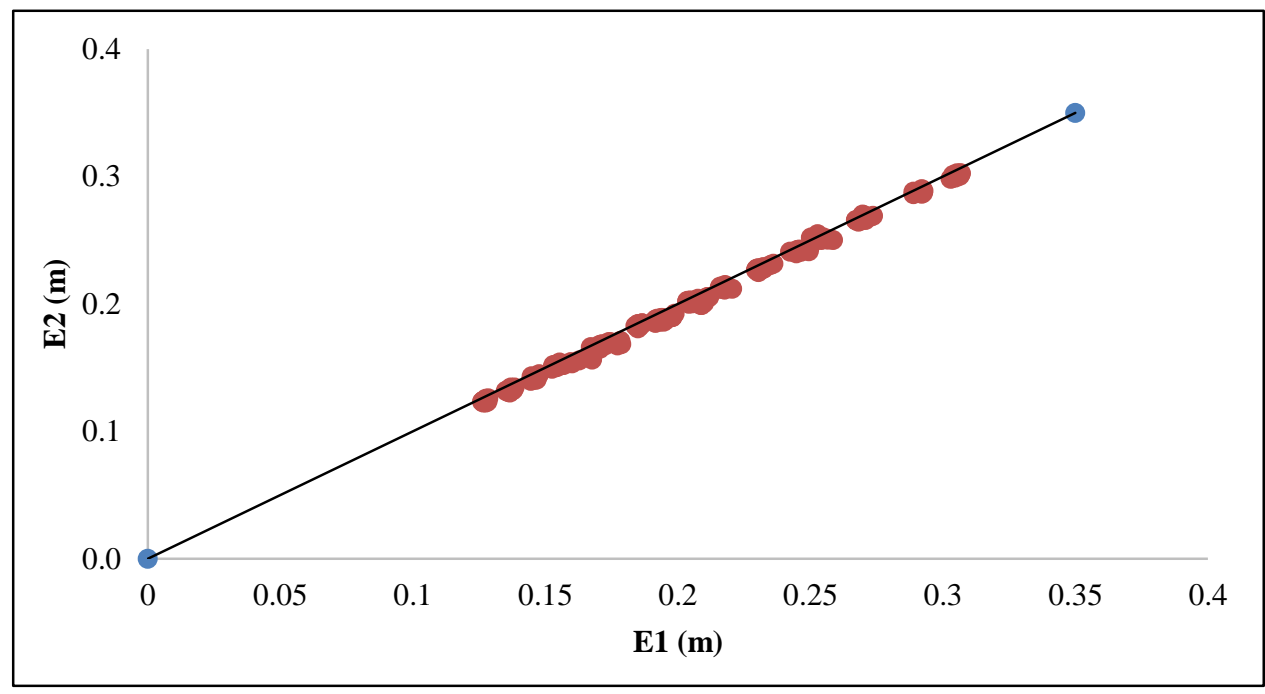

Figure 21. Primary and Secondary Energies of the Weir

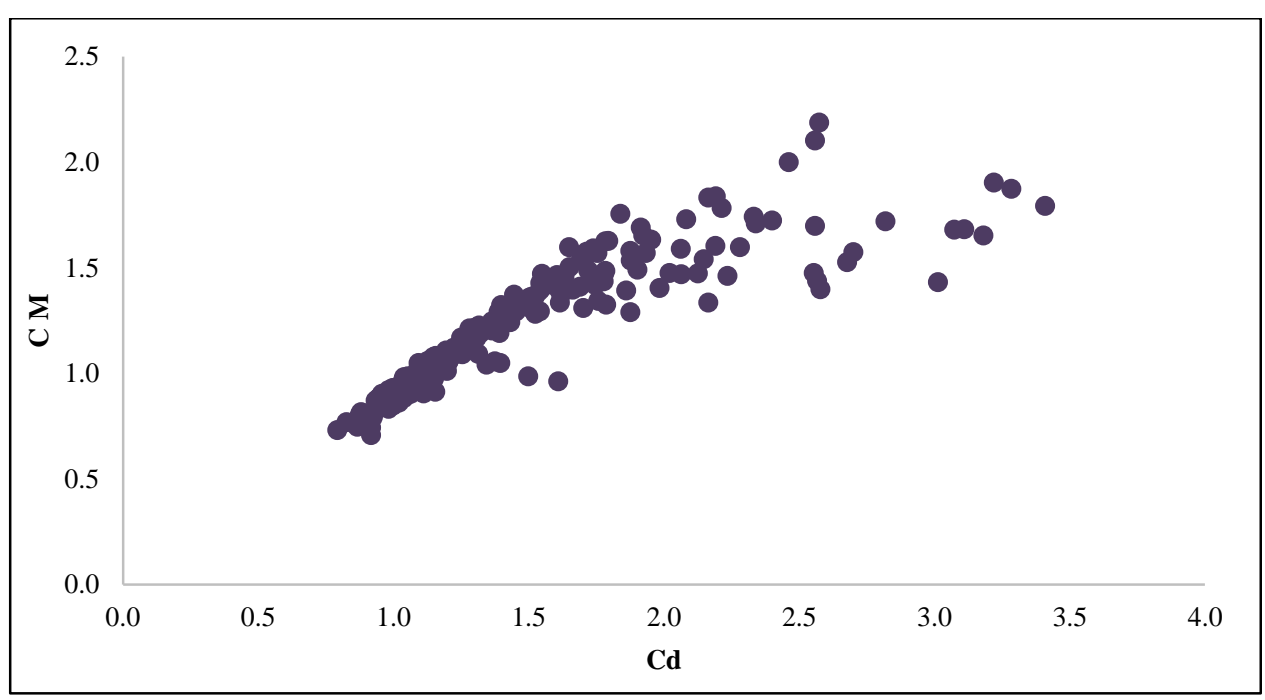

Figure 22. Discharge Coefficients of Cd and CM

\section{Conclusion}

This study was carried out in Soil Conservation and Watershed Management Research Institute (SCWMRI). With regard to the study results, the side trapezoidal piano key weir can function more properly than the labyrinth triangular and trapezoidal weirs. The comparison made in this research indicates that the discharge coefficient of the trapezoidal linear piano key rectangular weir is 1.5 times more than that of the side trapezoidal piano key weir. But, the discharge coefficient in a linear trapezoidal piano key weir is 1.55 times more than that of the linear rectangular piano key weir. The comparison made among the discharges of side trapezoidal piano key weir and side triangular and trapezoidal labyrinth weirs showed that the trapezoidal piano key side weir is capable of releasing a flow 1.2 times more than that of the linear trapezoidal labyrinth weir with 12 degrees angle and 1.87 times more than the one with 6 degrees angle, and 1.5 times more than that of the triangular labyrinth weir.

As for the Case 1, the weir with pier height of $15 \mathrm{~cm}$ and in the dimensionless ratio of $0.2<\mathrm{H} / \mathrm{P}<0.4$, has the highest discharge of $C_{M}-2.1$; and the weir with pier height of $20 \mathrm{~cm}$ and in the dimensionless ratio of $\mathrm{H} / \mathrm{P}<0.5$, has the highest 
discharge of $C_{M}-1.79$. As for the Case 2, the weir with pier height of $15 \mathrm{~cm}$ and in the dimensionless ratio of $0.2<\mathrm{H} / \mathrm{P}<0.4$, has the highest discharge of $C_{M}-2.2$; and the weir with pier height of $20 \mathrm{~cm}$ and in the dimensionless ratio of $\mathrm{H} / \mathrm{P}<0.5$, has the highest discharge of $C_{M}-1.63$.

\section{Acknowledgement}

This research was conducted in Soil Conservation and Watershed Management Research Institute (SCWMRI). Hereby, the authors express their gratitude to the authorities of the above Institute for their kind cooperation.

\section{Conflicts of Interest}

The authors declare no conflict of interest.

\section{References}

[1] Gandoshmin,A. and Norouzi,B. “3D hydrodynamics of curved piano key overflows on plan”. Journal of Hydraulic 9(3) (2014):6179. doi: 10.30482/jhyd.2014.10176.

[2] Abrishami, J. and Hosseini,M. "Hydraulic Open Canals:. Mashhad University Press, 19th edition (2017).

[3] Laugier, F. "Design and construction of the first Piano Key Weir (PKW) weir at the Goulours dam". Intl. J. Hydropower Dams 13(5) (2007):94-101.

[4] Lempérière, F., Vigny, J. P. and Ouamane, A. "General comments on Labyrinths and Piano Key Weirs: The past and present. Labyrinth and Piano Key Weirs”. London (2011):17-24. ISBN 978-0-415-682282-4.

[5] Anderson, R. M., and B. P. Tullis. "Piano Key Weir: Reservoir versus Channel Application.” Journal of Irrigation and Drainage Engineering 138, no. 8 (August 2012): 773-776. doi:10.1061/(asce)ir.1943-4774.0000464.

[6] Kabiri-Samani, Abdorreza, and Amir Javaheri. "Discharge Coefficients for Free and Submerged Flow over Piano Key Weirs." Journal of Hydraulic Research 50, no. 1 (January 13, 2012): 114-120. doi:10.1080/00221686.2011.647888.

[7] Kabiri-Samani, Abdorreza, Seyed Mahmood Borghei, and Hojat Esmaili. "Hydraulic Performance of Labyrinth Side Weirs Using Vanes or Piles." Proceedings of the Institution of Civil Engineers - Water Management 164, no. 5 (May 2011): $229-241$. doi:10.1680/wama.2011.164.5.229.

[8] Leite Ribeiro, M., J-L. Boillat, Anton Schleiss, F. Laugier, and C. Albalat. "Rehabilitation of St-Marc Dam Experimental Optimization of a Piano Key Weir." In Proceedings of the 32nd Congress of IAHR, no. CONF. 2007.

[9] Mehboudi, A., J. Attari, and S.A. Hosseini. "Experimental Study of Discharge Coefficient for Trapezoidal Piano Key Weirs." Flow Measurement and Instrumentation 50 (August 2016): 65-72. doi:10.1016/j.flowmeasinst.2016.06.005.

[10] Anderson, R. M., and B. P. Tullis. "Piano Key Weir: Reservoir Versus Channel Application.” Journal of Irrigation and Drainage Engineering 138, no. 8 (August 2012): 773-776. doi:10.1061/(asce)ir.1943-4774.0000464.

[11] Lefebvre, V., Vermeulen, J. and Blancher, B. "Influence of geometrical parameters on PK-Weirs discharge with 3D numerical analysis Labyrinth and piano key weirs-PKW”. CRCpress, London (2013):49-56.

[12] Oertel, M. "Discharge coefficients of piano key weirs from experimental and numerical models". 36th IAHR World Congress the Hague the Netherlands (2015).

[13] Karimi, Mahmoud, Jalal Attari, Mojtaba Saneie, and Mohammad Reza Jalili Ghazizadeh. "Side Weir Flow Characteristics: Comparison of Piano Key, Labyrinth, and Linear Types.” Journal of Hydraulic Engineering 144, no. 12 (December 2018): 04018075. doi:10.1061/(asce)hy.1943-7900.0001539.

[14] Oertel,M. "Piano Key Weir Research: State-of-the-art and Future Challenges". 17th International Symposium on Hydraulic Structures Utah State University Germany (2018).

[15] Kazemi, J.,Sanei,M.And Azhdari Moghadam,M. "Scale effect of the water surface profile on Ogee Weir with curvature in plan and Training Walls". Journal of Applied Research of Irrigation and Drainage Structures Engineering, 17(66) (2016): 119-136. doi: 10.22092/aridse.2016.106417.

[16] Erpicum, S., A. Silvestri, B. Dewals, P. Archambeau, M. Pirotton, M. Colombié, and L. Faramond. "Escouloubre Piano Key weir: Prototype versus scale models." Labyrinth and Piano Key Weirs II, CRC press. London, (2013): 65-72.

[17] Michelazzo, Giovanni. "New Analytical Formulation of De Marchi’s Model for a Zero-Height Side Weir." Journal of Hydraulic Engineering 141, no. 12 (December 2015): 04015030. doi:10.1061/(asce)hy.1943-7900.0001047. 
[18] Karimi, M., J. Attari, M. Saneie, and M. R. Jalili-Ghazizadeh. "Experimental study of discharge coefficient of a piano key side weir." In Labyrinth and Piano Key Weirs III: Proceedings of the 3rd International Workshop on Labyrinth and Piano Key Weirs (PKW 2017), February 22-24, 2017, Qui Nhon, Vietnam, p. 109. CRC Press, 2017.

[19] Oertel, M. "Sensitivity Analysis for Discharge Coefficients of Piano Key Weirs. Hydraulic Structures and Water System Management". 6th IAHR International Symposium on Hydraulic Structures Portland (2016):557-565.

[20] Crookston, B. M., and B. P. Tullis. "Hydraulic Design and Analysis of Labyrinth Weirs. I: Discharge Relationships.” Journal of Irrigation and Drainage Engineering 139, no. 5 (May 2013): 363-370. doi:10.1061/(asce)ir.1943-4774.0000558.

[21] Bilhan, Omer, M. Emin Emiroglu, and Carol J. Miller. "Experimental Investigation of Discharge Capacity of Labyrinth Weirs with and Without Nappe Breakers.” World Journal of Mechanics 06, no. 07 (2016): 207-221. doi:10.4236/wjm.2016.67017.

[22] Cicero, G, J Delisle, V Lefebvre, and J Vermeulen. "Experimental and Numerical Study of the Hydraulic Performance of a Trapezoidal Piano Key Weir.” Labyrinth and Piano Key Weirs II (October 17, 2013): 265-272. doi:10.1201/b15985-36.

[23] Aydin, M. Cihan, and M. Emin Emiroglu. "Determination of Capacity of Labyrinth Side Weir by CFD.” Flow Measurement and Instrumentation 29 (March 2013): 1-8. doi:10.1016/j.flowmeasinst.2012.09.008. 